\title{
ANTI-DEPRESSANTS AND CHILDREN: SUICIDALITY, OFF-LABEL USE, AND TRIAL PUBLICATION
}

\author{
Timothy J. Hixson*
}

\section{INTRODUCTION}

Antidepressants, specifically Selective Serotonin Reuptake Inhibitors (SSRIs), have been used to treat a plethora of neurological diseases, such as major depressive disorder (MDD) and obsessive compulsive disorder (OCD). ${ }^{1}$ The first SSRI medication available for prescription was Eli Lilly Company's Prozac, which received Food and Drug Administration (FDA) approval in $1987 .^{2}$ Initially, SSRIs were attractive to physicians because they appeared to have few side-effects and be more effective than previous medications. ${ }^{3}$ However, in 1990, questions arose as to whether SSRIs caused patients to commit suicide. ${ }^{4}$ Although there is some anecdotal evidence to support the theory that SSRIs cause suicide, there is little scientific evidence to support the claim, and the FDA has previously resisted placing "black box" labels (the strongest available) on SSRI medications. ${ }^{5}$

As SSRIs became more prevalent, doctors began prescribing them to adolescent and pediatric patients, although the drugs were not approved for such uses. ${ }^{6}$ These prescriptions, known as off-label prescriptions, have increased despite a lack of efficacy data and pediatric drug trials. ${ }^{7}$ Steps such as collecting efficacy data and performing drug trials are important because a drug safe for use in adults may not be safe for children due to metabolic and

* J.D. Candidate, 2006, Indiana University School of Law-Indianapolis; BA, 2003, Butler University, Indianapolis, Indiana.

1. Food \& Drug Admin., Public Health Advisory, Worsening Depression and Suicidality in Patients being Treated with Antidepressant Medications (Mar. 22, 2004), http://www.fda.gov/cder/drug/antidepressants/AntidepressanstPHA.htm (last visited Feb. 27, 2006).

2. Andrew E. Falsetti, Fluoxetine-Induced Suicidal Ideation: An Examination of the Medical Literature, Case Law, and the Legal Liability of Drug Manufacturers, 57 FooD \& DRUG L.J. 273, 274 (2002).

3. See Symposium, Supporting Materials: A Staff Compilation of Relevant Statutory, Statistical, and Case Materials, 8 U.C. DAvis J. JUV. L. \& PoL'Y 315, 334 (2004) [hereinafter Symposium].

4. Falsetti, supra note 2, at 275.

5. See generally id.

6. See Food \& Drug Admin., FDA Proposed Medication Guide: About Using Antidepressants in Children or Teenagers (Oct. 21, 2004), http://www.fda.gov/cder/drug/ antidepressants/SSRIMedicationGuide.htm (last visited Nov. 21, 2004).

7. Chris Adams \& Alison Young, Off-label Prescriptions Slipping by FDA, TALLAHASSEE DEMOCRAT, Nov. 4, 2003, http://www.tallahassee.com/mld/democrat/7175710 .htm?template=contentModules/prints... (last visited October 14, 2004). 
physiological differences between children and adults. ${ }^{8}$ Recent events have called into question the safety and efficacy of SSRIs when used in adolescents and children.' As a result, the FDA convened a group of experts to scrutinize data available from previous drug studies to determine whether a stronger warning should be placed on SSRI labels. ${ }^{10}$

The FDA's study resulted in the agency acknowledging that SSRIs could cause some children and teenagers to become suicidal, ${ }^{11}$ and raised questions concerning: manufacturer versus prescriber liability, pediatric drug testing and research, and publication of clinical/drug trial results. These questions are important for the legal and medical communities to consider not only because of the potential harm that may be caused by these drugs, but also their potential benefits.

\section{SUICIDE LINK}

\section{A. Depression and Suicide}

Part of the difficulty in determining whether SSRIs are causally linked to suicide is the nature of depression itself. Depression is widespread in the United States and suicidal ideation occurs in as many as ninety percent of all depressed patients. ${ }^{12}$ Furthermore, approximately fifteen percent of those suffering from depression will take their own lives. ${ }^{13}$ Overall, "suicide is the eighth leading cause of death in the United States and accounts for $1.5 \%$ of all annual deaths." ${ }^{\prime 14}$ As a result, it is often difficult to determine whether a suicide or suicidal ideation is caused by the SSRI medication rather than the underlying illness.

8. Gregory Hazard, Please, Sir, I Want Some More: Congress' Carrot-And-Stick Approach to Pediatric Testing Leaves Therapeutic Orphans Needing More Protection, $20 \mathrm{~J}$. CONTEMP. HEALTH L. \& POL'Y 467, 478-79 n. 64 (2004).

9. See Mary Ann Liebert, Clinical Trials, 23 B1OTECHNOLOGY L. REP. 567 (2004) (discussing GlaxoSmithKline withholding findings that its SSRI, Paxil, was no more effective than a placebo and may increase the risk of suicide).

10. Food \& Drug Admin., Talk Paper, FDA Updates Its Review of Antidepressant Drugs in Children (Aug. 20, 2004), http://www.fda.gov/bbs/topics/ANSWERS/2004/ANS01306.html (last visited Apr. 19, 2006).

11. Tell Truth About Antidepressants on Drug Labels and in Medical Journals, NEWSDAY, Sept. 15, 2004, at A42.

12. Falsetti, supra note 2, at 273.

13. Id.

14. Id. 


\section{B. Adults}

\section{Theories of Suicidality}

At their introduction, SSRIs were widely regarded as an important medical discovery. ${ }^{15}$ Physicians readily accepted SSRIs and began prescribing them to patients due to favorable clinical trial data, which indicated that SSRIs were more effective and "had far fewer dangerous side effects than other classes of antidepressants." 16 Despite the acceptance of the medical community and favorable drug trial data, shortly after the introduction of SSRIs, "reports describing SSRI-induced violence against self and others began to appear." Teicher and colleagues, which spurred further reports with theories alleging that SSRIs are linked to suicidality. ${ }^{18}$

There are three basic "direct causation" theories of SSRI-induced suicidality, and a fourth theory in which SSRIs are thought to have an indirect causal relationship. ${ }^{19}$ The basic theories are: 1) the initiative theory; 2) the efficacy theory; and 3) the "rollback phenomena." ${ }^{20}$ Under initiative theory, it is thought that depressed patients will "regain initiative and energy before an improvement in cognition and mood occurs, and this could mobilize an individual to carry out suicidal thoughts." ${ }^{21}$ Efficacy theory suggests that in situations where the medication is ineffective, the patient may commit suicide either due to the natural progression of the disease or discouragement resulting from treatment failure. ${ }^{22}$ The theory of "rollback phenomena" suggests that SSRIs will work to relieve depression "in the reverse order in which it manifested itself; thus, if the patient previously had experienced a period of suicidal ideation, it may reappear with continued treatment."23

The fourth theory of suicidality suggests that the suicidal ideation is truly in response to a severe form of psychomotor agitation known as akathisia. ${ }^{24}$ Akathisia is an inner sense of restlessness and an inability to sit still, which patients often describe as feeling like they are "jumping out of their skin."25 This theory suggests a link between akathisia and suicidal

15. Symposium, supra note 3, at 334.

16. Id.

17. Id.

18. Falsetti, supra note 2, at 275.

19. Id. at 274-76.

20. Id.

21. Id. at 274.

22. Id.

23. Falsetti, supra note 2, at 274.

24. Id. See also Miller v. Pfizer, Inc., 196 F. Supp. 2d 1095, 1109 (D. Kan. 2002).

25. Falsetti, supra note 2, at 274-75. 
ideation. ${ }^{26}$ It is suggested that under this theory suicidal ideation is an extreme response to the unpleasant sensation produced by akathisia and "not true suicidal ideation as is typically described by depressed patients experiencing suicidal ideation."27

\section{Scientific Link}

Regardless of the theories of how SSRIs may cause suicide, the underlying question is whether there is a true scientific causal relationship between SSRIs and suicide. The FDA, drug manufacturers, and other agencies have studied this possible link since just after the first anecdotal reports were published in $1990 .{ }^{28}$ In 1991, 1992, 1997, and 2002, the FDA conducted periodic safety reviews on this issue, and "each time f[ound] no scientific basis for a warning that SSRIs cause suicide." ${ }^{29}$ Often the nature of depression itself makes it difficult to ascertain one distinct cause for a patient's suicide. The FDA has recognized that "although antidepressants in general may have the ability to cause suicidal ideation, its occurrence is too rare to be affirmatively attributed to the drugs, and that depression itself is a cause of suicide. $" 30$

Despite the lack of scientific evidence to support a claim that SSRIs cause suicide, the anecdotal evidence has been enough to persuade people who could benefit from the drugs not to use them. ${ }^{31}$ When considering the question of whether SSRIs cause suicide it is important to consider the benefits these drugs could have in a patient's life. As the court noted in the recent case of Miller v. Pfizer, Inc.:

[W] hatever the explanation, studies of suicide rates among fluoxetine users have not indicated an increased risk of suicide attempts or completions, relative to users of other antidepressants; in fact, [the most recent textbook by the American Psychiatric Association] notes that larger controlled studies have confirmed that suicide rates among depressed patients treated with fluoxetine (and all other antidepressants) are markedly reduced from those of depressed patients who do not receive antidepressants. ${ }^{32}$

26. See Miller v. Pfizer, Inc., 196 F. Supp. 2d 1095, 1109 (D. Kan. 2002); Cloud v. Pfizer, Inc., 198 F. Supp. 2d 1118, 1123 (D. Ariz. 2001).

27. Cloud, 198 F. Supp. 2d at 1123 (D. Ariz. 2001).

28. See Needleman v. Pfizer, Inc., 2004 WL 1773697, at *2 (N.D. Tex. 2004).

29. Id.

30. Falsetti, supra note 2, at 279.

31. Id.

32. Miller, 196 F. Supp. 2d at 1109 (D. Kan. 2002)(citing American Psyc. Assoc., TEXTBOOK OF PSYCHIATRY (3d. edition 1999)). 
Additionally, the American College of Neuropsychopharmacology (ACN) notes several shortcomings common to the case reports suggesting a link between SSRIs and suicidal ideation. ${ }^{33}$ Reports suggesting a link between SSRIs and suicidal ideation failed to distinguish between the potential contribution of the disease process, external stressors, and the medication. ${ }^{34}$ Also, such suicidal ideation is not specific to any one type of antidepressant, which suggests that the suicidal ideation may be a manifestation of the disease itself. ${ }^{35}$

In light of this evidence, and the shortcomings of the reports suggesting a link between SSRIs and suicidality, the American College of Neuropsychopharmacology issued a consensus statement that concluded:

There is no evidence that antidepressants such as the selective serotonin reuptake inhibitors [SSRIs], for example, fluoxetine [Prozac], trigger emergent suicidal ideation over and above rates that may be associated with depression and other antidepressants. What is clear is that most patients receive substantial benefit from treatment with this drug and related antidepressants. ${ }^{36}$

An ACN Task Force Review further concluded that "new generation lowtoxicity antidepressants, including SSRIs, may carry a lower risk for suicide than older TCAs [tricyclic antidepressants]." ${ }^{\text {77 }}$ Nearly all scientific reviews of the issue agree that although suicidal ideation may emerge during treatment with antidepressants, a causal relationship between suicidality and antidepressant drugs cannot be established. ${ }^{38}$

Nevertheless, the research of the ACN, the FDA, and other groups that have studied the issue do not address SSRI use in children and adolescents. The studies used by these groups focused almost exclusively on the effect of SSRIs in adults, and the data should not be simply applied to children without modification. Instead, additional studies should be performed taking into account the important metabolic and physiological differences between children and adults. ${ }^{39}$

33. Id. at 1112 (citations omitted).

34. Id.

35. Id.

36. Id.

37. Miller, 196 F. Supp. 2d at 1114 (quoting M. Goldblatt \& M. Silverman, Psychopharmacological Treatment of Suicidal Patients, in REVIEW OF SUICIDOLOGY 143-44 (R. Maris, S. Canetto, J. McIntosh, M. Silverman eds., 1999).

38. Miller, 196 F. Supp. 2d at 1109.

39. See Hazard, supra note 8. 


\section{Children}

\section{Differences in Testing for Children and Adults}

Testing of new or marketed drugs on children was not required by the FDA until $1997 .^{40}$ Prior to 1997 , the FDA merely prohibited drug companies from marketing drugs for pediatric purposes if they had not been tested on children for safety and efficacy. ${ }^{41}$ This regulatory scheme had an unintended dual effect; not only did it protect children from false and misleading claims on drug labels, but it also discouraged pharmaceutical companies from testing new drugs on children..$^{42}$ As a result, there was very little, if any, information available to pediatricians prescribing drugs to children. The lack of information forced pediatricians to speculate on proper dosages or avoid prescribing a potentially beneficial drug altogether. ${ }^{43}$

Particularized studies for pediatric patients are especially important because children undergo rapid metabolic and physiological changes, thereby creating a need to fine-tune dosages based on the rate of elimination of a drug from a child's system. ${ }^{44}$ Despite the importance of pediatric studies, by the time the FDA began addressing the problem, only twenty percent of drugs were labeled for use in children, and six of the ten leading drugs prescribed by pediatricians had never been tested on children. ${ }^{45}$ SSRIs provide a terrific illustration of the inadequacies of such a system.

Despite a dearth of safety and efficacy data and an absence of guidelines for use in children, SSRI prescriptions for children and adolescents have increased greatly in recent years. ${ }^{46}$ In fact, SSRIs have come to be viewed as safe and effective for children and are widely prescribed, notwithstanding their lack of approval for use in children. Additionally, physicians prescribe SSRIs to children for a variety of psychiatric illnesses outside of the approved uses. ${ }^{47}$ As a result, children are placed in the undesirable and dangerous position of de facto guinea pigs for pediatric experimentation outside the scope of a controlled and relatively safe drug trial. ${ }^{48}$ Thus, children are less

40. Hazard, supra note 8 , at 478.

41. Id.

42. Id.

43. Id.

44. Id. at 477.

45. Hazard, supra note 8, at 478.

46. Symposium, supra note 3, at 334-35.

47. Id. See Food \& Drug Admin., Public Health Advisory, Suicidality in Children and Adolescents Being Treated with Antidepressant Medications (Oct. 15, 2004), http://www.fda.gov/cder/drug/antidepressants/SSRIPHA200410.htm. ("Among . . . antidepressants, only Prozac is approved for use in treating MDD in pediatric patients. Prozac, Zoloft, Luvox, and Anafranil are approved for OCD in pediatric patients. None of the drugs is approved for other psychiatric indications in children.") (last visited April 14, 2006).

48. Hazard, supra note 8, at 478-79. 
likely to receive the most effective treatment available, and there is a lack of reliable efficacy data available to allow pediatricians to make the best and most informed choice when prescribing drugs.

\section{Recent Developments of SSRI Use in Children}

SSRI use in children has come under heavy attack recently as several agencies have declared them unsafe for use in children. For example, New York Attorney General Elliot Spitzer sued GlaxoSmithKline, the maker of Paxil, for withholding data that showed that Paxil was ineffective for children.$^{49}$ Most of the current interest in SSRI use in children was spurred by the Medicines and Healthcare Products Regulatory Agency's (MHRA) (Britain's equivalent to the FDA) statement on June 10, 2003 that the SSRI Seroxat (marketed as Paxil in the U.S.) must not be used for treatment of children. ${ }^{50}$ After reviewing data from clinical trials conducted by pharmaceutical companies, the MHRA's Committee on Safety of Medicines (CSM) concluded that for six of the seven SSRIs investigated, the risks of suicide and suicidal ideation outweigh any benefits in children with depression, and therefore SSRIs should not be used for pediatric patients. ${ }^{51}$

After the MHRA announcement in June 2003, the FDA and other groups began taking a closer look at SSRI use in children. Twelve of fifteen subsequent studies of SSRIs failed to show that the drugs were effective in children. $^{52}$ Initial studies on Paxil appeared to suggest an increased risk of suicidal thoughts and actions in children who were given Paxil when compared to children given placebos. ${ }^{53}$ Subsequent studies of other SSRIs indicated that children on these medications may also have an increased risk of suicidal thoughts and behaviors. ${ }^{54}$ After reviewing the data from studies performed on all SSRI drugs, the members of the FDA Psychopharmacologic Drugs and Pediatric Advisory Committees determined that the finding of an increased risk of suicidality in pediatric patients applied to all of the drugs studied in controlled clinical trials. ${ }^{55}$ The results from these studies led the FDA to conduct one final study on suicidality combining results of twentyfour smaller studies of children and teenagers who took either a sugar pill or

49. See Jeffery Krasner, SEC Focusing on Drug Makers; Full Disclosure of Tests Called Key, Bost. GL., Sept. 27, 2004, at C4, available at 2004 WL 59807884.

50. Symposium, supra note 3.

51. Id.

52. Olympian News Services, FDA Blocked Data on Children and Antidepressants, Sept. 10, 2004, http://www.antidepressantsfacts.com/2004-09-10-FDA-blocked-SSRI-data-kids.htm (last visited Apr. 17, 2006).

53. FDA, Talk Paper, supra note 10.

54. Id.

55. Food \& Drug Admin., Statement, FDA Statement on Recommendations of the Psychopharmacologic Drugs and Pediatric Advisory Committees (Sept. 16, 2004), http://www.fda.gov/bbs/topics/news/2004/NEW01116.html (last visited Nov. 21, 2004). 
antidepressants for one to four months. ${ }^{56}$ Data collected from this study, known as the Columbia Study, showed that two children out of every hundred on placebos became suicidal, while four out of every hundred children on antidepressants became suicidal. ${ }^{57}$ The results of this study were instrumental in the FDA's ultimate decision to place a "black box" warning on all SSRI drugs.

\section{Columbia Study}

\section{a. Method and results}

The FDA organized the Columbia Study because of concerns about whether the varied events identified in earlier studies as possibly suicide related could reasonably be considered to represent suicidality. ${ }^{58}$ The original studies and clinical trials of SSRIs in pediatric patients lacked a systematic or standardized language to define suicidal behavior. ${ }^{59}$ "This lack of standardized terminology for suicidal acts [made] it difficult to interpret the meaning of reported adverse events (AEs) that occurred" in the original studies. ${ }^{60}$ In order to provide a more accurate account of suicidality, the FDA needed to ensure that definitions of suicidality in earlier studies were consistent with each other. ${ }^{61}$. To meet the goal of consistent terminology, the FDA asked Columbia University to assemble a panel of pediatric suicidality experts to undertake a blind review of the reported behaviors using a rigorous classification system. ${ }^{62}$

The tasks of the Columbia Study included identifying adverse events in previous studies "that were inappropriately classified as suicidal," or suicidal AEs that were missed altogether, in order to avoid misinterpretation of the SSRI trial data. ${ }^{63}$ Before interpreting the data, Columbia Study clinicians agreed upon terminology "using research-supported definitions that [were] both valid (relevant features have been shown to be associated with the definition) and reliable (clinicians are able to use these definitions in similar ways)" for determining whether an AE was a suicidal event. ${ }^{64}$ After agreeing on terminology and participating in training sessions, the members of the Columbia Study "systematically review[ed] over 400 case descriptions from

56. FDA Proposed Medication Guide, supra note 53.

57. Id.

58. FDA Talk Paper, supra note 10.

59. Food \& Drug Admin., Background Information on the Suicidality Classification Project(Mar. 22, 2004), http://www.fda.gov/cder/drug/antidepressants/classificationProject.htm (last visited Oct. 7, 2004).

60. Id.

61. See FDA Talk Paper, supra note 10.

62. Id.

63. Background Information, supra note 59.

64. Id. 
the twenty-five pediatric trials ...."65 The Columbia Study reviewed "all events that were originally described as possibly suicidal, . . . coded as accidental injuries, and all serious adverse events." ${ }^{.66}$ After reviewing the events, the members of the study classified the events into three categories: "suicidal events (suicide attempts, aborted attempts, ... interrupted attempts, and suicidal ideation-related events); non-suicidal events (self-injury or mutilation without suicidal intent, events attributable to other psychiatric symptoms, medical or accidental injuries); and indeterminate events (nonconsensus or unable to classify due to limited data)."

The Columbia Study reanalyzed data from published and unpublished pediatric trials of SSRIs conducted between 1983 and 2001. ${ }^{68}$ After the Columbia Study finished reviewing the data from the pediatric trials, Tareck Hammad, an FDA medical reviewer, analyzed the Columbia research to assess the risk of suicidal tendencies. ${ }^{69}$ Hammad concluded:

that minors given the nine antidepressants had been 1.78 times more likely to have exhibited suicidal behavior than those taking placebos. The rate was significantly higher for some antidepressants, especially Wyeth's Effexor (4.97) and Anglo-American GlaxoSmithKline PLC's. Paxil (2.65). Hammad September 13 told the advisory panel that out of 100 minors taking antidepressants, two or three would become suicidal due to short-term use of the drug.... The analyses by Hammad and the Columbia team backed up an earlier analysis by FDA epidemiologist Andrew Mosholder, who in February [2004] had concluded that minors taking antidepressants were 1.89 times as likely to show suicidal tendencies. ${ }^{70}$

As a result of the data from the Columbia Study, the FDA determined that a "black box" warning was appropriate for SSRI labels."

\section{b. Possible Problems with the Columbia Study}

Although the FDA determined that "black box" warnings were appropriate based on the conclusions of the Columbia Study, the study still

65. Id.

66. Id.

67. Id.

68. Medicine and Health; FDA Backs Child Antidepressant Warnings; Other Developments, FACTS ON FILE WORLD NEWs Dig., Sept. 30, 2004, at $756 \mathrm{C} 3$.

69. Id.

70. Id.

71. Public Health Advisory, supra note 47. 
contained several flaws. To a large extent, the Columbia study relied on data submitted to the FDA from the drug companies themselves, and much of the data provided was incomplete. ${ }^{72}$ In addition to incomplete data, reliance on data provided by drug companies could have other policy implications as well. By relying on data from the pharmaceutical companies, the FDA left the door open to misleading and possibly false data designed to protect the companies' interests. ${ }^{73}$ It is not an uncommon practice for pharmaceutical companies to emphasize favorable data while obscuring or excluding data that may be harmful to their ability to sell a drug, ${ }^{74}$ thus stricter guidelines are necessary to allow the FDA to properly interpret the available data.

Additionally, the very nature of the Columbia Study may have made it difficult to ensure that the results of the Study were truly accurate. The very purpose of the study indicates that the Columbia researchers were dealing with data that had serious shortcomings. ${ }^{75}$ At the time the original data were compiled, the researchers "were not looking for suicidal behavior as a possible adverse event."76 As a result it is likely that many incidents were not only incorrectly categorized, but not recorded at all. ${ }^{77}$ Since suicidality was not an expected effect of the drugs, it is unlikely that the original studies provided a control to determine the cause of the emergent suicidal ideation. ${ }^{78}$

Another factor that may reduce the accuracy of the Columbia group's determination is the fact that drug-company trials often confuse selfdestructiveness with suicide attempts. ${ }^{79}$ When determining whether an act is suicidal in nature or merely self-destructive, intent is the controlling factor. ${ }^{80}$ If an individual lacks the intent to commit suicide, then the self-destructive act cannot be classified as suicidal in nature. "Dr. Thomas Laughren, leader of the FDA's psychiatric drug products group, noted that the [brief notes provided by the] drug companies . . . were often poor" which made discovering the underlying intent difficult. ${ }^{82}$ As he stated, "[w]e did not have the level of detail in these cases that one would have liked to do a rational classification." 83

72. See FDA Study Confirms Link Between Antidepressants, Child Suicide, DRUG INDUST. DAILY, Aug. 11, 2004, §156.

73. See Liebert, supra note 9 (discussing GlaxoSmithKline withholding findings that their SSRI, Paxil, was no more effective than placebo and may increase the risk of suicide).

74. Id.

75. See DRUG INDUST. DAILY, supra note 72.

76. Id.

77. See Background Information, supra note 59.

78. See DRUG INDUST. DAILY, supra note 72.

79. Gardiner Harris, Antidepressants Restudied for Relation to Child Suicide, N.Y.TIMES, June 20, 2004, $\$ 1$ at 20.

80. Id.

81. Id.

82. Id.

83. Id. 
Another difficulty results from the diversified nature of the original trials. Each pharmaceutical trial is unique in several ways that may compromise the integrity of the Columbia group's determination. Since each individual trial is focused for unique purposes, there is no single constant method utilized. Dosages, methods of administration, and subject group will be almost as varied as the number of trials themselves. ${ }^{84}$ Given the inherent differences in the original trials, it calls into question how the Columbia researchers can be sure, after mere second hand review of clinical notes, that at least some of the adverse reactions were not caused by unusually high dosages, or another external factor, rather than the drug itself. How can one be sure that this collection and review of suboptimal data may be reduced to a concrete and conclusive result? ${ }^{85}$

\section{New FDA Warnings}

Relying on the Columbia Study's findings, the FDA Psychopharmacologic Drugs and Pediatric Advisory Committees (PDPAC) issued the following findings and recommendations to the FDA:

Increased risk of suicidality in pediatric patients applied to all the drugs studied (Prozac, Zoloft, Remeron, Paxil, Effexor, Celexa Wellbutrin, Luvox and serzone) in controlled clinical trials;

That any warning related to an increased risk of suicidality in pediatric patients should be applied to all antidepressant drugs, including those that have not been studied in controlled clinical trials ... ;

[R]eached a split decision . . . regarding recommending a "black box" warning related to an increased risk for suicidality in pediatric patients for all antidepressant drugs; . . .

[R]ecommended that the products not be contraindicated in this country because the Committees thought access to these therapies was important for those who could benefit ... ${ }^{86}$

84. See Andrew D. Mosholder, M.D., M.P.H., Review and Evaluation of Clinical Data (Sertraline) (Aug. 13, 2002), available at http://www.fda.gov/cder/foi/esum/2004/ 19839SE5_044_20990SE5-010Zoloft_MO_Review2FIN.pdf (last visited Feb. 27, 2006); Andrew D. Mosholder, M.D., M.P.H., Review and Evaluation of Clinical Data (Paxil) (Oct. 7, 2002), available at http://www.fda.gov/cder/foi/esum/2004/20031s037_ paxil_Clincal_BPCA_FIN.pdf (last visited Feb. 27, 2006).

85. See, DRUG INDUST. DAILY, supra note 72.

86. Statement on Recommendations, supra note 55. 
The FDA generally supported the findings of the PDPAC and began working toward adopting new labeling with regard to SSRIs. ${ }^{87}$

On October 15, 2004, the FDA announced its new strategy to warn the public regarding the increased risk of suicidality in children and adolescents being treated with SSRI medications. ${ }^{88}$ As of October 15, 2004, the FDA began directing SSRI manufacturers to place a "black box" warning on the drug label ${ }^{89}$ and that patients should be given a Patient Medication Guide (MedGuide) "advis[ing] them of the risk and precautions that can be taken."

Black box warnings are the most serious warning labels available to the FDA. When used, the drug manufacturer is restricted from certain actions. ${ }^{91}$ For example, pharmaceutical companies may not run advertisements to remind health care professionals of a product's availability if the product carries a black box warning. ${ }^{92}$ Until the issuance of a black box warning for SSRI medications, only ten drug products approved for children contained a black box warning about their use in children. ${ }^{93}$ Although the black box warning is serious, it is important to recognize that the FDA does not prohibit the use of SSRIs in children and adolescents. The FDA recognizes that the illnesses

87. Id.

88. Food and Drug Admin., FDA News, FDA Launches a Multi-Pronged Strategy to Strengthen Safeguards for Children Treated with Antidepressant Medications (Oct. 15, 2004), available at http://www.fda.gov/bbs/topics/news/2004/NEW01 124.html (last visited Apr. 19, 2006).

89. Public Health Advisory, supra note 47. Based on these data [from the "Columbia" study], FDA has determined that the following points are appropriate for inclusion in the boxed warning:

- Antidepressants increase the risk of suicidal thinking and behavior (suicidality) in children and adolescents with MDD and other psychiatric disorders.

- Anyone considering the use of an antidepressant in a child or adolescent for any clinical use must balance the risk of increased suicidality with clinical need.

- Patients who are started on therapy should be observed closely for clinical worsening, suicidality, or unusual changes in behavior.

- Families and caregivers should be advised to closely observe the patient and communicate with the prescriber.

- A statement regarding whether the particular drug is approved for any pediatric indication(s) and, if so, which one(s).

Among the antidepressants, only Prozac is approved for use in treating MDD in pediatric patients. Prozac, Zoloft, Luvox, and Anafranil are approved for OCD in pediatric patients. None of the drugs is approved for other psychiatric indications in children.

See Public Health Advisory, supra note 47.

90. Food \& Drug Admin. News, supra note 88.

91. Id.

92. Id.

93. Id. 
SSRIs are designed to treat have serious consequences if not appropriately treated, but those taking SSRIs should be fully informed of the dangers. ${ }^{94}$

\section{OFF-LABEL USES}

Currently, there is only one SSRI, Prozac, approved by the FDA for treating children with MDD. ${ }^{95}$ In addition to Prozac, three other SSRI medications are approved for treating OCD in pediatric patients. ${ }^{96}$ However, doctors have routinely prescribed these medications outside the scope of these approved uses in order to meet the best interests of their patients. This is known as "off-label use," which is defined as "[t]he use of a drug to treat a condition for which it has not been approved by the U.S. Food and Drug Administration (FDA), esp[ecially] when such use may relieve unpleasant symptoms, or prove compassionate." 97 Since so few drugs are approved for use in children, the use of off-label prescribing is especially prevalent in the realm of pediatric care. ${ }^{98}$ While this may often be in the best interest of the child, it causes some confusion in determining who bears liability for the harmful effects of the drugs; the physician or the pharmaceutical manufacturer?

\section{A. History}

The role of the FDA in the United States is to assess the safety and effectiveness of all drugs before they can be sold. ${ }^{99}$ Unfortunately a large portion of drugs sold in the United States are avoiding FDA scrutiny through off-label prescribing, basically prescriptions of unapproved uses. ${ }^{100}$ This practice has become common if not the standard of care in many instances, ${ }^{101}$ but places the patient at risk while offering no assurances that the drugs will work. ${ }^{102}$ The FDA drug approval process currently takes the following form:

The FDA must approve each drug marketed in the United States. Once the "New Drug Application" is filed, the

94. Id.

95. Public Health Advisory, supra note 47.

96. Id.

97. Tardy v. Eli Lilly \& Co., 2004 WL 1925536 at *1 n.3 (Me. Super. Ct. 2004) (quoting TABER's CYCLOPEDIC MEDICAL DICTIONARY (F.A. Davis Inc., 2002).

98. See Hazard, supra note 8, at 478.

99. Adams \& Young, supra note 7.

100. Id.

101. See Kaspar J. Stoffelmayr, Products Liability and "Off-Label" Uses of Prescription Drugs, 63 U. CHI. L. REV. 275 (1996); ALA. CODE § 27-1-10.1 (2004); CAL. INS. CODE § 10123.195 (2004); CONN. GEN. STAT. ANN. § 38a-492b (West 2004); KAN. STAT. ANN. § 402,167, 2,170 (2003); MD. CODE ANN. INS. § 15-804 (2004).

102. Adams \& Young, supra note 7. 
applicant must show that the proposed drug is safe and effective for its intended use. This is usually accomplished with the results of clinical trials. Clinical investigators must be qualified, and the testing typically involves controlled experiments. The promoter of the drug must also submit a proposed label that will accompany the drug. If the application meets FDA standards, the Agency will approve the drug for the particular use or uses included in the application and will also approve the proposed label. This approval process is both extremely costly and time consuming.

Once the FDA has approved a drug, the manufacturer may only market the product for the approved uses. Because the FDA-approved label must reflect those uses, any other use of the product is deemed "off-label." "Misbranding," which includes off-label marketing, is prohibited by the FDCA [Food, Drug, and Cosmetic Act]. These regulatory guidelines are complicated by an important feature of the law of offlabel use and promotion: physicians may prescribe drugs for non-approved or off-label uses. Thus, a doctor may know that a particular drug is effective for one indication but only FDA-approved for a different indication. In this common scenario, the doctor may prescribe the drug for the unapproved use, even though the manufacturer may not promote it for that use. ${ }^{103}$

When a drug exhibits properties that have not been specifically proven in a clinical trial, these properties may be exploited through the use of off-label prescriptions for unproven uses. ${ }^{104}$ This allows a drug company to profit from the use of the drug while avoiding the strict data requirements, rigorous scrutiny, and cost of the FDA drug approval process. ${ }^{105}$

Off-label prescribing is a rapidly growing practice, or as some view it, a rapidly growing problem. It is estimated that nearly one-half of all American drug prescriptions are for off-label uses. ${ }^{106}$ Part of the reason for the growth of off-label prescribing is a lack of incentive for the drug manufacturers to seek approval for new uses for prescription drugs. Seeking approval for new uses would likely have little effect on drug sales, so the

103. Mark Ford, Another Use of Oxycontin: The Case for Enhancing Liability for OffLabel Drug Marketing, 83 B.U. L. REV. 429, 431-32 (2003).

104. Tardy v. Eli Lilly \& Co., 2004 WL 1925536 at *1 n.3 (Me. Super. 2004)(quoting TABER's CYCLOPEDIC MEDICAL DICTIONARY (F.A. Davis Inc., 2002).

105. See id.

106. See Stoffelmayr, supra note 101, at 275. 
benefit to drug manufacturers does not outweigh the costs of the approval process. ${ }^{107}$ Additionally, when new uses are discovered, less than the entire patent term remains for the drug. Therefore, even with extended patent terms, it is difficult for a drug manufacturer to recover its investment in having an off-label use approved. ${ }^{108}$

\section{B. Off-label Prescriptions and Children}

Off-label prescribing encompasses more than simply using a drug for an unapproved use. One common form of off-label prescribing in children is when a drug is used for its approved use but in an unapproved patient population, such as when children are prescribed drugs approved for use in adults only. ${ }^{109}$ When prescribing off-label for children, physicians necessarily take a greater role in the administration of that drug. ${ }^{110}$ For example, when prescribing off-label, physicians must calculate the proper dosage based on the patient's age and weight, and often the solutions must be compounded based on physician or pharmacist experience due to the absence of pediatric formulations. ${ }^{111}$

The FDA recognizes many of the inadequacies of prescribing guidelines for many drugs commonly used in children. ${ }^{112}$ New standards have been developed to address some of these problems unique to the pediatric patient population, most importantly in the new drug application process. ${ }^{113}$ In the past, manufacturers applied for approval for a new drug under the presumption that pediatric studies would not be conducted. However, new approval standards require manufacturers to explain why a pediatric study will not be conducted as part of the application process. ${ }^{114}$

\section{Manufacturer vs. Prescriber Liability}

\section{Off-label Marketing}

There is a long history and tradition in the United States of restricting the claims manufacturers may make about their drugs in advertising. Prior to the 1970s, regulations prevented manufacturers from marketing drugs to the

107. See Id. at 277.

108. $I d$.

109. Id.

110. Veronica Henry, Off-Label Prescribing Legal Implications, 20 J. LEGAL MED. 365, 380 (1999).

111. Id.

112. Id.

113. Id. These new standards allow extrapolation from adult clinical trials and the use of pediatric pharmacokinetics (the study of the process by which a drug is absorbed, distributed, metabolized, and eliminated from the body) in formulating pediatric use guidelines.

114. Id. 
consuming public. Rather, companies focused advertising on the doctors prescribing the drugs. ${ }^{115}$ In the early 1970 s, however, the restrictions on direct promotion were lessened for the narrow purpose of providing price comparisons to consumers but did not allow advertisements to consumers to include any representations of the drug's safety, effectiveness, or indications. ${ }^{116}$ In the mid 1980s, the FDA lifted the advertising moratorium on safety, effectiveness, and indications, ${ }^{117}$ and by the 1990 s, direct to consumer advertising became more commonplace. However, manufacturers are still subject to limitations on the claims they may make about their drugs. ${ }^{118}$ Of special importance to the issue of manufacturer or prescriber liability for off-label use of SSRIs in children are the provisions that prohibit manufacturers from advertising or promoting unapproved uses for their drugs, or including instructions for offlabel uses in the drug labels. ${ }^{119}$ These provisions are important because they

115. See Peter Barton Hutt \& Richard A. Merill, FoOd \& Drug LaW: CASES AND MATERIALS 465 (2d ed. 1991).

116. $I d$.

117. Id.

118. Advertising claims by manufacturers are subject to 21 C.F.R. $\S 202.1(\mathrm{e})(4)$ (year), which provides in part:

(ii) In the case of an advertisement for a prescription drug other than a drug the labeling of which causes it to be an unapproved "new drug" and other than drugs covered by paragraph (e)(4)(i) of this section, an advertisement may recommend and suggest the drug only for those uses contained in the labeling thereof:

(a) For which the drug is generally recognized as safe and effective among experts qualified by scientific training and experience to evaluate the safety and effectiveness of such drugs; or

(b) For which there exists substantial evidence of safety and effectiveness, consisting of adequate and well-controlled investigations, including clinical investigations (as used in this section "clinical investigations," "clinical experience," and "clinical significance" mean in the case of drugs intended for administration to man, investigations, experience, or significance in humans, and in the case of drugs intended for administration to other animals, investigations, experience, or significance in the specie or species for which the drug is advertised), by experts qualified by scientific training and experience to evaluate the safety and effectiveness of the drug involved, on the basis of which it can fairly and responsibly be concluded by such experts that the drug is safe and effective for such uses; or

(c) For which there exists substantial clinical experience (as used in this section this means substantial clinical experience adequately documented in medical literature or by other data (to be supplied to the Food and Drug Administration, if requested)), on the basis of which it can fairly and responsibly be concluded by qualified experts that the drug is safe and effective for such uses; or

(d) For which safety is supported under any of the preceding clauses in paragraphs (e)(4)(iii)(a), (b), and (c) of this section and effectiveness is supported under any other of such clauses.

119. Stoffelmayr, supra note 101, at 279. 
serve as a basis for shifting liability of off-label uses from the prescribing physician to the manufacturer. ${ }^{120}$

Despite the FDA's safeguards, drug companies have become very successful in indirectly promoting off-label uses. ${ }^{121}$ Generally, methods employed by the drug companies to promote off-label uses are well within what the FDA allows, although some methods are considered less than ethical. Some of the most common methods of promoting off-label use include: "funding research into off-label drug uses, sponsoring continuing education programs and symposia in which ostensibly independent researchers discuss off-label uses, distributing reprints of journal articles on off-label uses, and purchasing special journal supplements that feature articles about off-label uses."122 All of these methods are permitted by the FDA as long as the drug manufacturers follow rules designed to ensure that the research remains objective. $^{123}$

Other restrictions upon drug manufacturers include regulations regarding shipment of drugs. It is illegal under federal law to ship a new drug interstate unless it is the subject of an approved new drug application. ${ }^{124}$ Federal law defines a new drug as: "[a]ny drug . . . not generally recognized, ... as safe and effective for use under the condition prescribed, recommended, or suggested in the labeling . ..."125 Therefore, manufacturers face liability if a drug is shipped containing information regarding off-label uses. ${ }^{126}$ It is important to remember that FDA approval for a drug's shipment is limited to the intended uses as approved by the FDA. ${ }^{127}$ The intended use for a drug is not limited to the actual label on the packaging, but includes any statement in advertising, "promotional material, or oral statements by the manufacture or

120. See Richard HeAfEy \& Don M. KenNedy, Product LiabiltTy: WinNing STRATEGIES AND TECHNIQUES (8th prtg. 2001) (discussing application of the learned intermediary doctrine).

121. Stoffelmayr, supra note 101, at 279-80.

122. Id. at 280 .

123. $I d$.

Less ethical efforts by manufacturers to promote off-label drug uses include, for example, paying physicians to participate in sham "seeding trials," in which physicians prescribe off-label drug therapies as part of supposed scientific studies that in reality serve only to introduce participating physicians and their colleagues to the off-label uses.

124. 21 U.S.C.A. § 355(a) (West 2004); Marsha Cohen, Commentary: Can We Talk? About Food and Drug Regulation and the First Amendment, 58 FoOD \& DRUG L.J. 741, 745 (2003).

125. 21 U.S.C.A $\S 321(p)(1)$ (West 2004).

126. Cohen, supra note 124 , at 745 . Stating:

It is undisputed that if Compound $X$ has been approved in a $100 \mathrm{mg}$. dose, four times a day, for headache, it is illegal to ship Compound $X$ in a $200 \mathrm{mg}$. dose, or for use six times a day, or for nausea. A drug may be proven safe and effective for one use, but be neither safe nor effective for another. Different uses are simply not interchangeable.

127. Id. 
its representative."128 As a result, manufacturers face liability for illegally shipping a drug if it advertises an unapproved use. ${ }^{129}$

Despite the liabilities imposed on manufacturers for advertising unapproved uses, these uses are far from illegal. In fact, the off-label uses are recognized by the FDA and play a vital role in American healthcare. ${ }^{130} \mathrm{~A}$ manufacturer effectively limits its liability by following the FDA guidelines in advertising, labeling, and promoting its drug. After the FDA approves a drug for any use, the actual prescription choices are left to the discretion of the physician, ${ }^{131}$ thereby potentially placing liability for any ill-effects for offlabel use on the prescribing physician. However, the liability may not shift to the physician if the manufacturer failed to adequately warn the physician of the risks.

\section{Failure to Warn}

One dispositive issue in products liability cases against drug manufacturers is whether the manufacturer provided sufficient warning of the drug's risks. ${ }^{132}$ Manufacturers are only required to warn of risks of which they know or should know. ${ }^{133}$ However, this does not allow manufacturers to purposely remain ignorant of the risks of their product. In determining whether a drug manufacturer adequately warned of the risks, the court holds the manufacturer up as an expert in the field. ${ }^{134}$ FDA regulations also impose other duties upon manufacturers to discover the risks of the drug. ${ }^{135}$ Therefore, manufacturers are deemed to have constructive knowledge of all documented risks associated with the drug. ${ }^{136}$

In addition to being liable for failing to warn for risks of the drug, manufacturers have a duty to warn of foreseeable misuses of the drug. ${ }^{137}$ This duty generally arises out of actions subsequent to the manufacturer's

128. Id. (quoting Jonathan S. Kahan \& Jefferey K. Shapiro, The First Amendment and the Food and Drug Administration's Regulation of Labeling and Advertising: Three Proposed Reforms, 58 Food \& Drug L.J. 353, 360 (2003)).

129. Id.

130. HUTT \& MERILL, supra note 115, at 616-17 (noting, however, that although off-label uses often represent sound medical care they can be abused and "represent poor judgment ... or inadequate medical training.").

131. Cohen, supra note 124 , at 745.

132. Stoffelmayr, supra note 101, at 282.

133. Id. at 283.

134. Id.

135. Id. (Manufacturers must "carefully monitor reports from physicians-whether made directly to manufacturers or published in the medical literature-regarding injuries related to their drugs .... Manufacturers also have a duty to conduct postmarketing studies on the safety of their drugs and to monitor for and investigate possible undetected risks.").

136. Id.

137. HEAFEY \& KENNEDY, supra note 120. 
production of the drug and can develop over time. ${ }^{138}$ Such a duty arises when a drug is commonly prescribed for off-label uses, or when such uses constitute a substantial portion of the prescribed uses, ${ }^{139}$ such as in treating cancer or AIDS..$^{140}$

The nature of "foreseeable misuse" often makes it difficult for drug manufacturers to adequately warn of certain risks. Off-label uses of drugs develop over time, and therefore may not be expected or foreseeable at the time the drug is approved and marketed. As a result the approved labeling of the drug often does not adequately address common off-label uses of many drugs. However, drug manufacturers must receive FDA approval for any changes made to the drug label and warning, even if the desired result is a stronger warning message. ${ }^{141}$ As a result, many of these off-label uses are not addressed and unnecessary harm results. This is because a manufacturer was unable to gain FDA approval for new warning messages or the approval process caused significant delay. ${ }^{142}$

138. Liability for "foreseeable misuse" usually, but not always, develops over time as doctors accumulate data from off-label prescriptions and scholarly journals indicating possible uses for a drug. As a method of prescription gains acceptance over time the manufacturer may face liability under "foreseeable misuse." However, such liability may arise at the time the drug is introduced for marketing, and may be created by the drug company itself. As one court noted, " $[\mathrm{I}] \mathrm{f}$ the manufacturer negligently overpromotes its products, or downplays their dangerous effects, it will not be relieved of liability for the foreseeable misuse of the drug and resulting injuries." Evraets v. Intermedics Intraocular, Inc., 34 Cal.Rptr.2d 852, 860 (Cal. Ct. App. 1994) (citations omitted).

139. Anderson v. Hedstrom Corp., 76 F.Supp.2d 422, 439-40 (S.D.N.Y. 1999)(quoting Liriano v. Hobart Corp., 700 N.E. 2d 303, 305, 307 (1998)) ("Such a duty will generally arise where a defect or danger is revealed by user operation and brought to the attention of the manufacturer ...").

140. Daniel B. Klein and Alexander T. Tabarrot, "Who Certifies Off-Label?", REGULATION, Vol. 27, No. 2, p 60-63 (Summer 2004). "Most cancer and AIDS patients are given drugs that are not FDA-certified for the prescribed use. In a large number of fields, a majority of patients are prescribed at least one drug off-label, and in some cases the off-label prescription is the 'gold-standard' treatment."

141. See Stoffelmayr, supra note 101 at 285-86.

142. Some of this difficulty can be seen in the reasoning and arguments found in Needleman v. Pfizer, Inc.:

The FDA has clearly determined that a warning linking Zoloft and suicide would be false, misleading, and harmful to patients. Plaintiffs' inadequate warning claim would thus conflict with the federal requirements imposed during the regulation of Zoloft; in effect allowing a state regulation to impose labeling requirements contrary to those required by federal law....

Plaintiffs' "failure to warn claim" seeks to impose liability on Pfizer for not including a warning in Zoloft packaging that indicates a relationship between Zoloft and suicide. In response, Pfizer argues that such a statement would be considered "false and misleading" by the FDA, and would directly conflict with the FDCA. See 21 U.S.C. \$355(d) (grounds for refusing a new drug application) ....

Needleman v. Pfizer, Inc., 2004 WL 1773697 at *2 (N.D. Tex. 2004) (italics in original). TRIAL LAWYERSOF AMERICA, Governing Product Safety: Are Government Regulatory Agencies Doing 
Despite the duties placed on manufacturers to adequately warn of a drug's risks, plaintiffs still face a difficult road in seeking recovery. A plaintiff must prove two elements to recover on a failure to warn claim. The plaintiff must show that 1) the drug caused the injury; and 2) that a different or alternate warning would have changed the decision to prescribe the drug. ${ }^{143}$ It is often the second element that proves the most significant hurdle in drug manufacturer liability cases. Even if the drug is proven to have caused the injury, the plaintiff must show that the warning provided by the manufacturer was relied upon. ${ }^{144}$ There are two aspects to this element that make it difficult for the plaintiff to overcome: 1) who must rely on the warning (the choice of the word prescribe in the element suggests that it is the doctor who must be warned, which is discussed below); and 2) proof of reliance. For example, a plaintiff may not recover if he or she did not read the included warning, even if that warning would have been inadequate if relied upon. ${ }^{145}$

\section{Learned Intermediary Doctrine}

The learned intermediary doctrine is very important in drug liability cases because it resolves the questions of who the drug company must warn and who must rely on that warning and it insulates the drug companies from liability for off-label prescriptions. Under this doctrine, the drug company fulfills its obligations by informing the prescribing doctor of a drug's inherent risks. ${ }^{146}$ Courts apply the learned intermediary doctrine on a case-by-case basis. However, it is applied almost universally in cases involving prescription drugs and medical devices because the doctrine takes into account

Enough to Ensure that Consumer Products Are Safe? Two Attorneys from Consumers Union Discuss the System's Weaknesses and Needed Improvements, 40 TRIAL 26, 28 (Nov. 2004) ("FDA regulations are the 'ceiling' as well as the 'floor' of requirements for drug makers.").

143. See Miller, 196 F. Supp. at 1124 (2002).

144. See id.

145. HEAFEY \& KENNEDY supra note 120 at $\S 10.03$; see also, Motus v. Pfizer, Inc., 358 F.3d 659, 661 (9th Cir. 2004) ("Because the doctor testified that he did not read the warning label that accompanied Zoloft or rely on information provided by [Pfizer] . . the adequacy of Pfizer's warnings is irrelevant .... [Therefore] a product defect claim based on insufficient warnings cannot survive summary judgment if stronger warnings would not have altered the conduct of the prescribing physician.").

146. Miller, 196 F. Supp. 2d at 1121 (2002) (citing Nichols v. Cent. Merch., Inc., 16 Kan.App.2d 65, 67, 817 P.2d 1131, 1133 (Kan. Ct. App. 1991)). 
the complex role physicians play in the treatment of patients. ${ }^{147}$ As a result, this doctrine effectively relieves a manufacturer of liability.

In the case of SSRIs, manufacturers may be relieved of liability even if they failed to adequately warn the medical community ${ }^{148}$ Nevertheless, some courts have rejected the doctrine in cases involving drugs and medical devices for contraception and some vaccines. ${ }^{149}$ These courts have rejected the learned intermediary doctrine in cases involving contraception because the choice of contraception is personal rather than medical, thus the consumer is entitled to direct communication from the drug manufacturers in order to make her decision. ${ }^{150}$ The doctrine has not applied in cases where vaccines "were administered to all comers in a 'clinic-type' setting without a physicians particularized weighing of the product's risks and benefits for each recipient ...."151 It is highly unlikely that courts will reject the learned intermediary doctrine for cases involving SSRIs because the typical SSRI patient requires a physician's attention.

Unlike the decision to use contraceptives, the decision to use an SSRI is not primarily a personal choice. Instead, SSRIs are used to treat serious medical conditions and diseases diagnosed by a physician, rather than as ways to avoid undesired circumstances. The treatment of depression is not simply a matter of the patient's will, but requires the consultation, consideration, and diagnosis of a medical professional.

Additionally, the need for diagnosis and physician directed treatment for depression and other SSRI indications distinguishes the use of SSRIs from clinic-administered vaccines. For example, SSRIs are not administered en masse to the public like vaccinations during the flu season. Unlike clinical vaccinations, SSRIs are prescribed only after proper diagnoses thereby providing the patient the benefit of the "physician's particularized weighing of the product's risks and benefits for [that] recipient." 152

147. With respect to drugs and medical devices, the prescribing physician is viewed as a "learned intermediary" whose specialized knowledge and experience enable him or her to evaluate the complex and technical information in the warning and assess the product's risks and benefits in treating a particular patient. Application of the learned intermediary doctrine in the context of prescription products also reflects concern that direct patient warnings on prescription products would interfere with the doctorpatient relationship.

HEAFEY \& KENNEDY, supra note $120, \S 10.03$.

148. Id. (noting that if the prescribing physician did not rely on the warning, or was aware of the risk from other sources, the physician's conduct is considered the superseding cause that breaks the chain of liability).

149. Id.

150. Id.

151. Id.

152. HEAFEY \& KENNEDY, supra note $120, \S 10.03$. 
The learned intermediary doctrine places liability upon the prescribing physician. It is the physician's duty to adequately weigh the risks and rewards of a particular course of treatment when prescribing medication. Whether the physician has met this duty depends not only on the warnings provided by the manufacturer, but also the prevailing knowledge in the field. ${ }^{153}$ For SSRIs, the prevalent knowledge in the field can play an important role because of the ongoing debate about SSRIs and suicidality. Although much of the literature indicates that SSRIs do not cause suicidality, the vigorous and public nature of claims of a relationship between SSRIs and suicidality could serve to put a physician on notice beyond the warnings included on the drug label. ${ }^{154}$

Although drug manufacturers may avoid liability through the learned intermediary doctrine, there are still complaints surrounding manufacturers' decisions regarding clinical trials. ${ }^{155}$ The questions raised cast doubt on whether doctors and the FDA are able to rely on clinical data as accurate representations of the drug when choosing to prescribe the drug or grant approval for marketing. Controversy surrounding the publication of trial results has been highlighted by SSRI manufacturers who have chosen not to publish unfavorable clinical results. ${ }^{156}$

\section{Clinical Trials}

Clinical trials are vital to the healthcare industry for several reasons. These trials are the basis for FDA approval, and they influence the physician's decision to administer a drug for certain indications. Companies are required by the FDA to rigorously test new drugs to show that they are safe, effective, and ready for marketing. Therefore, a company's failure to disclose all information found in clinical trials can have a serious impact on the consuming public. This impact is especially true with the prevalence of offlabel uses since doctors rely on data from clinical studies in determining if an off-label use may be appropriate for a particular patient. With the debate surrounding SSRIs, it was particularly disconcerting when GlaxoSmithKline admitted in 2004 that it had not revealed clinical data suggesting their SSRI, Paxil, may increase the risk of suicidality in children. ${ }^{157}$ To truly understand the impact of the decision of what a drug manufacturer does and does not

153. HEAFEY \& KENNEDY, supra note $120, \S 10.03$ (stating that drug manufacturers may not be liable if the physician is aware of the danger from another source).

154. Stoffelmayr, supra note 101 , at 283 (arguing that manufacturers have constructive, if not actual, knowledge of adverse effects documented in the field, perhaps this can also be applied to physicians who prescribe drugs that are widely speculated to pose a risk to a certain patient category).

155. See David Bjerklie, Putting Trials on the Record, Time Mag., July 5, 2004 at 42 (stating drug trials are misleading due to data that is left out).

156. Liebert, supra note 9, at 567.

157. Id. 
publish, one must understand the approval process and the duties of the manufacturer.

\section{A. New Drug Approval}

Before a manufacturer can introduce a drug into commerce it must gain FDA approval for the intended use by showing the drug is safe and effective for its intended use. ${ }^{158}$ In order to show that the drug is safe and effective, the manufacturers must conduct clinical trials in controlled studies for the intended patient group. Additionally, manufacturers must provide the FDA with information regarding the method, population, and dosages of the clinical trial. At this stage of the testing, companies are required to provide the FDA with data from all trials. Still, the approval process remains flawed because until very recently, the FDA did not require drug companies to test new drugs in pediatric populations. ${ }^{159}$ Thus, the approval process left a void in an important area of FDA concern.

158. (a) Necessity of effective approval of application

No person shall introduce or deliver for introduction into interstate commerce any new drug, unless an approval of an application filed pursuant to subsection

(b) or (j) of this section is effective with respect to such drug.

(b) Filing application; contents

(1) Any person may file with the Secretary an application with respect to any drug subject to the provisions of subsection (a) of this section. Such person shall submit to the Secretary as a part of the application (A) full reports of investigations which have been made to show whether or not such drug is safe for use and whether such drug is effective in use; (B) a full list of the articles used as components of such drug; (C) a full statement of the composition of such drug; (D) a full description of the methods used in, and the facilities and controls used for, the manufacture, processing, and packing of such drug; (E) such samples of such drug and of the articles used as components thereof as the Secretary may require; (F) specimens of the labeling proposed to be used for such drug. The applicant shall file with the application the patent number and the expiration date of any patent which claims the drug for which the applicant submitted the application or which claims a method of using such drug and with respect to which a claim of patent infringement could reasonably be asserted if a person not licensed by the owner engaged in the manufacture, use, or sale of the drug. If an application is filed under this subsection for a drug and a patent which claims such drug or a method of using such drug is issued after the filing date but before approval of the application, the applicant shall amend the application to include the information required by the preceding sentence. Upon approval of the application, the Secretary shall publish information submitted under the two preceding sentences. The Secretary shall, in consultation with the Director of the National Institutes of Health and with representatives of the drug manufacturing industry, review and develop guidance, as appropriate, on the inclusion of women and minorities in clinical trials required by clause (A), and (G) any assessments required under section $355 \mathrm{c}$ of this title.

21 U.S.C.A. § 355 (West 2004).

159. Hazard, supra note 8, at 478-79. 


\section{B. Pediatric Research}

The FDA did not require pediatric testing of new drugs until 1997. ${ }^{160}$ Instead, the FDA attempted to ensure that the companies did not market drugs for pediatric use unless pediatric testing had been conducted. ${ }^{161}$ Unfortunately, this method did not adequately protect children because it deterred pediatric research rather than encourage it, even when the drug was widely used in pediatric populations through off-label use. ${ }^{162}$ Nothing was being done to ensure that off-label uses were safe for children and very little research was done concerning the possible effects these drugs may have on a highly sensitive population. ${ }^{163}$

Under the earlier regulation scheme the FDA's attempts to protect children were almost completely without effect. These early schemes included incentives for voluntary testing, and later, drug companies were only required to test a product in pediatric studies if they articulated a reason it would be used in children. Therefore, virtually no burden was placed upon the companies to ensure pediatric safety, placing children in a figurative "black hole" in terms of clinical knowledge and regulatory protection. ${ }^{164}$ Manufacturers merely avoided marketing drugs to children and left room for off-label uses to fill the need for pediatric care, which resulted in children becoming "de facto research subjects ... deprived of the [protection] of the controlled supervision of a clinical trial." 165

To address the problems presented by the regulatory scheme, the FDA promulgated the "Final Rule" in 1997. ${ }^{166}$ This rule was composed of three parts (1) the rule applied to both new and marketed drugs widely used in children; (2) the FDA "could require clinical data for all pediatric subpopulations;" and (3) if a manufacture met certain criteria, it could obtain a full or partial waiver for its product. ${ }^{167}$ Under the Final Rule, if a manufacturer failed to conduct pediatric trials, the FDA could deem the drug misbranded. ${ }^{168}$ However, just prior to the promulgation of the Final Rule,

160. Id. at 478.

161. Id.

162. This regulatory approach evinced a shield and a sword on the marketplace. While protecting children from false or misleading claims on drug labels, it also deterred pharmaceutical companies from testing drugs on children. Thus, pediatricians were left to speculate appropriate dosages to treat their young patients or

Id. otherwise avoid prescribing drugs altogether....

163. Id. at 479.

164. See Randall Baldwin Clark, 9 U. Chi. L. Sch. Roundtable 1, Speed, Safety and Dignity: Pediatric Pharmaceutical Development in an Age of Optimism, 10-13 (2002).

165. Hazard, supra note 8, at 478-79.

166. Id. at 484.

167. Id.

168. Id. at 489. 
Congress passed the Food and Drug Administration Modernization Act of 1997 (FDAMA), which called for voluntary pediatric testing. ${ }^{169}$ The FDAMA sought to encourage pediatric testing by providing incentives to the manufacturer rather than threatening sanctions. ${ }^{170}$ With the passage of the FDAMA, the FDA's authority to promulgate the Final Rule was immediately called into question and fell into general non-enforcement until the court officially determined that the Final Rule was outside the bounds of FDA authority. ${ }^{171}$ Unfortunately, the FDAMA did not adequately meet the needs that the Final Rule was promulgated to address. ${ }^{172}$

As the FDAMA approached sunset, Congress pushed for a new statute to take its place. In 2001, President Bush signed the Best Pharmaceuticals for Children Act (BPCA), the successor of FDAMA, into law. ${ }^{173}$ The BPCA contains essentially the same requirements as the FDAMA and likewise did not provide the FDA with the power necessary to protect pediatric patients. ${ }^{174}$ Therefore, Congress sought to augment the BPCA and in 2003, Congress enacted the Pediatric Research Equity Act of 2003 (PREA). ${ }^{175}$ The PREA codifies many of the provisions of the Final Rule and requires drug manufacturers to conduct pediatric testing for new drugs, unless the manufacturer can show that pediatric testing would be "impossible or highly impracticable," thus placing the burden on the manufacturer. ${ }^{176}$ The implementation provides an interesting dichotomy in pediatric testing requirements; pediatric testing is not mandatory, but drug companies receive lucrative incentives for carrying out pediatric clinical trials. ${ }^{177}$ Still, the PREA fails to address the serious risks posed by a lack of clinical data for off-label uses and does not present a final solution. $^{178}$

169. See id. at 485

170. Hazard, supra note 8, at 484-86 (stating that FDAMA provides six month patent extension for manufacturers who conducted pediatric tests).

171. Id. at 489.

172. TRIAL LAWYERS OF AMERICA, supra note 142, at 28 ("pharmaceutical companies regularly violate[d] [FDAMA which] requir[ed] them to disclose clinical trials... [I]n fact, the law has no enforcement mechanism and provides no penalties."). Source is not very neutral.

173. 21 U.S.C.A. § 355a (West 2004); Hazard, supra note 8, at 493.

174. Like the FDAMA, the BPCA provides a six month patent extension in return for voluntary pediatric clinical testing. Also, like the FDAMA, BPCA provides a six month patent extension in return for voluntary pediatric clinical testing. Also, like the FDAMA, "the BPCA ... maintain[e] the voluntary incentive scheme" to encourage pharmaceutical companies to test more of their drugs on children, with the result of better labeling and greater therapeutic indications for pediatric populations. See Hazard, supra note 8, at 491-2, 495.

175. 21 U.S.C.A. $\$ 355 \mathrm{c}$ (West 2004); Id. at 500.

176. Hazard, supra note 8 , at 500 .

177. Id. at $502-03$.

178. Promulgation of the PREA does not sufficiently remedy the shortcomings of the BPCA. Although pediatric clinical testing is now mandatory in new drugs, already marketed drugs may escape the burden of conducting research on children ... While the PREA ensures that the newest drugs will be tested on children, 


\section{Recent Developments/Required Publication}

Doctors and pharmacists rely on data from clinical trials when determining a course of treatment. Data required for premarket approval is very reliable and widely available. However, when a manufacturer performs testing after the drug is approved, generally to determine secondary uses, a manufacturer may choose not to publish negative trials and provide the medical journals only with the data from the most attractive trials. ${ }^{179}$ Thus, a large amount of clinical data is suspect, and may not provide physicians with a clear picture of the risks surrounding a medication. Indeed, it has been noted that "one of the greatest roadblocks to understanding the safety and efficacy of trials is the lack of public access and ... disclosure of these data sets ...." 180

Concerns over trial publication recently garnered more attention due to reports showing that GlaxoSmithKline published reports on the success of its SSRI (Paxil), but withheld findings that the drug was no more effective than the placebo in pediatric populations and may increase the risk of suicide. ${ }^{181}$ The FDA did not recognize that SSRIs may cause suicidality in children and teenagers because drug makers were permitted to bury clinical trial results when outcomes were bad or inconclusive. This is exactly what happened when trials suggested a link between SSRIs and suicide. ${ }^{182}$ Currently, there is a push from both Congress and the nation's medical journals to require that drug companies publish all clinical trials. ${ }^{183}$

In the wake of GlaxoSmithKline's admission and the FDA's implementation of the black box label on SSRIs, several prestigious medical

pediatricians may still find a dearth of information on drugs the commonly prescribe...

Moreover, combining the incentive structure of the BPCA with the mandatory PREA is contradictory ... Congress has codified both mandatory and incentive-based initiatives ... In attempting to placate the pharmaceutical industry while addressing the problems of off-label prescribing for children, Congress has created a legislative paradox: the law requires drug companies to test their products on children, and when they comply with the law, they receive a lucrative reward. It is the same perplexing logic that led the United States District Court for the District of Columbia to conclude that an incentive scheme and a "command and control approach" were incompatible, in striking down the FDA Final Rule.

Id. at 503-04.

179. Liebert, supra note 9.

180. Symposium, supra note 3, at 338.

181. Liebert, supra note 9.

182. Tell the Truth About Antidepressants on Drug Labels and in Medical Journals, NEWSDAY, Sept. 15, 2004, at A42.

183. Missing Drug Data, WASH. Post, June 30, 2004, at A20. 
journals ${ }^{184}$ began requiring drug companies to publicly register a trial before enrolling patients as a prerequisite for publication. ${ }^{185}$. Such a registration plan would fall short of requiring publication of all trial data, but could provide greater public awareness of trials and generate public concern if a large number of registered trials are not later published. ${ }^{186}$ Still, the efficacy of such an approach is questionable. Registry systems are likely to inundate the public with more registered trials than can easily be sorted and identified. Furthermore, the public may not know how to utilize the information for their safety, or worse, those who may effectively use the information may not even be aware of the system's existence. Because they are implemented at the journal level, these registry systems are an excellent first step in fighting data suppression for several reasons. Since they are implemented at the journal level, they are implemented quickly and efficiently, provide effective economic incentive to the manufacturers ${ }^{187}$, and can be done with relatively little cost. Yet, due to the systems shortcomings it remains merely a first step.

One possible way to augment the changes initiated at the journal level is with legislative action requiring drug companies to publish trial results. Two bills have been introduced, one in the House and one in the Senate, and each proposes a combined registry-publication system. ${ }^{188}$ The purpose of these proposals has two elements, (1) "to create a centralized and comprehensive" registry of clinical trials, and (2) "to make the information contained in the registry available to researchers, health care providers, patients seeking to enroll" in clinical trials, and the general public. ${ }^{189}$ While the bills are slightly different, each seeks to meet these goals in essentially the same fashion. Companies would be required to register their anticipated trials prior to commencement, provide an anticipated conclusion date, and update the registry with the results of the trial. ${ }^{190}$ Similarly, each bill seeks to enforce

184. See Liebert, supra note 9 (mentioning the New England Journal of Medicine, Annals of Internal Medicine, and Lancet as being part of the group.)

185. NEWSDAY, supra note 179 ("Companies can choose not to register trials, but that would mean forgoing the marketing boost of journal publicity.").

186. See Bjerklie, supra note 155 ("A registry won't mean that every failed trial will be published, but it will make it clear that those trials took place.").

187. Inside the Industry Medical Journals: Editors to Publish Only Registered Trials, AM. Pol. NeTWORK-AM. HeALTH LINE, Vol. 10 No. 9, Sept. 9, 2004.

188. Christopher Rowland, Bill to Seek Posting Results of Drug Trials, Under Plan, FDA Could Fine Firms that Fail to Comply, Boston GLOBE, Sept. 9, 2004, at D1; Fair Access to Clinical Trials Act of 2004, S. 2933, 108th Cong. (2004); Fair Access to Clinical Trials Act, H.R. 5252, 108th Cong. (2004).

189. S. 2933.

190. In General-

(1) CONDITIONS FOR FINANCIAL AWARDS- Except as provided in paragraph (2), an entity may not receive an award of a grant, contract, or cooperative agreement under this Act for the conduct of a clinical trial to determine the safety or effectiveness of a use of a drug or device (referred to in this section as a 'product') unless the responsible person for the trial-- 
the registry provisions through a combination of denying federal funding and imposing heavy fines. ${ }^{191}$ Each of these bills would be a terrific tool in protecting consumers, but neither successfully passed through committee. Despite not overcoming this hurdle, these bills still provide a framework for how Congress may deal with this issue in the future. The current legislative session may see similar legislation introduced.

(A) agrees to register the trial with the Secretary in accordance with subsection (d)(1);

(B) agrees to provide to the Secretary information on the results of the trial in accordance with subsection (d)(2);

(C) agrees to the disclosure to the public of information regarding the trial ...

H.R. 5252.

3) The data bank shall include a registry of clinical trials (whether federally or privately funded) in accordance with the following:

(A) The registry shall include the information required under subparagraph (B) for all clinical trials conducted to test the safety or effectiveness (including comparative effectiveness) of any drug, biological product, or device (including those drugs, biological products, or devices approved or cleared by the Secretary), except those Phase I clinical trials conducted to test solely the safety of an unapproved drug or unlicensed biological product. The registry may include Phase I clinical trials conducted to test solely the safety of an unapproved drug or unlicensed biological product with the consent of the responsible person. For purposes of this subparagraph, Phase I clinical trials are trials described in section 313.12(a) of title 21, Code of Federal Regulations (or any successor regulations).

(B) The information required under this subparagraph with respect to the clinical trial involved includes the following:

(i) A description of the purpose of the clinical trial, including the drug, biological product, or device to be tested.

(ii) The eligibility criteria for participation in the clinical trial.

(iii) A description of the location of trial sites and the start date of the trial.

(iv) A point of contact for those wanting to enroll in the trial, including the identity of the responsible person.

(v) The funding source or sources of the trial.

(vi) The estimated completion date for the trial. For purposes of this section, the term 'completion date' means the date of the final collection of data from subjects in the trial for the outcomes described in clause (vii).

(vii) A description of the primary and secondary clinical outcomes to be examined in the trial, the time at which the primary and secondary outcomes will be assessed, and the dates and details of any revisions to such outcomes.

(viii) The actual completion date of the trial and the reasons for any difference from such actual date and the estimated completion date submitted pursuant to clause (vi). If the trial is not completed, the termination date and reasons for such termination.

(ix) A summary of the results of the trial, including summary data tables, with respect to its primary and secondary outcomes as described in clause (vii), including information on the statistical significance or lack thereof of such results.

(x) Safety data concerning the trial (including a summary of adverse events specifying the number and type of such events).

S. 2933.

191. S. 2933 (Imposing fines of up to $\$ 10,000$ per day for every day of non-compliance after a thirty day notice period); H.R. 5252 (g)(A)(ii)(Imposing the same $\$ 10,000$ a day fine, but with $\$ 15,000$ cap for non-profit organizations). 


\section{CONCLUSION}

The current debate surrounding SSRI use in children is vital in many respects. SSRIs play an important role in pediatric care despite the FDA's determination that SSRI use in children may increase the risk of suicide. Ongoing study of SSRIs in pediatric subjects will greatly reduce the risks associated with pediatric SSRI use and may lead to the discovery of doses that are effective and safe for use in children.

At this time manufacturers are not liable for adverse reactions to SSRIs as long as they do not promote off-label uses of these drugs and provide the physician with adequate warning. Instead, the liability is appropriately placed upon the physician to seriously weigh the risks and benefits of the drug and share those determinations with the patient's parent(s) or guardian(s). If, however, a drug company purposely prevented the dissemination of data pertinent to a physician's risk-weighing analysis, then the insulation of the physician should be terminated to allow recovery from the drug company itself.

Perhaps the most important aspect of the SSRI controversy is how it illustrates the strengths and weaknesses of the current regulatory scheme. The FDA's attempts to protect the consumer are often futile due to holes in the system; yet the holes, such as off-label prescribing, can play a vital role in health care and the advancement of medical treatment. Such a paradox may never achieve a complete resolution, yet more can be done to fill these holes, whether through trial registry or some other form of regulation not yet contemplated.

Children deserve the same access to essential medications as adults. It is unfortunate that the recent FDA recognition of a link between SSRIs and suicide may scare away many patients who could benefit from SSRI treatment. Adults have used SSRIs for many years and have experienced great improvement in their quality of life. There has been more than a decade of studies conducted on SSRIs that show that these drugs do not lead to suicide in adults, and only one secondary study showing a link between SSRIs and suicide in children. This difference can be attributed to the unique physiological and metabolic processes in children and adolescents, and more rigorous pediatric testing requirements may help determine the difference at an earlier point. Through testing, an appropriate dosage level and treatment course could have been determined, which may eliminate the risk of suicidality. Instead doctors were forced to "guess" in their treatment of childhood depression.

The majority of the steps taken by the FDA are necessary to ensure that children and parents are aware of the risks before they begin SSRI treatment, yet some of the FDA's actions may have been a little overzealous. The previous warnings on SSRI labels indicated the inherent risks of suicide as a part of depression and urged close monitoring of SSRI patients. By adding the 
black box warning, patients may be scared away from reaping the benefits of these drugs. In mandating the black box warning, the FDA relied on the Columbia study which undertook the daunting task of reanalyzing data from twenty-five studies on pediatric SSRI use, each of which found no link between SSRIs and suicide in children. The Columbia Study results may be due to incomplete data and discrepancies between the methods used in the original studies (such as disparities in dosage: a study for sertraline used adult dosages while other studies used significantly decreased dosages). In relying on the Columbia Study, the FDA ignored years of research and may have acted too quickly.

Several SSRIs have already been approved for use in children with a variety of illnesses. While these drugs have proven safe and effective for their approved uses, the FDA's decision may cause some children to forego the beneficial SSRI treatment. 